This item was submitted to Loughborough's Research Repository by the author.

Items in Figshare are protected by copyright, with all rights reserved, unless otherwise indicated.

\title{
Reducing the potential for injury in the home. How can Ergonomics help?
}

PLEASE CITE THE PUBLISHED VERSION

http://www.ergonomics.org.uk/

PUBLISHER

(c) Taylor and Francis

VERSION

AM (Accepted Manuscript)

LICENCE

CC BY-NC-ND 4.0

REPOSITORY RECORD

McDermott, Hilary, Roger Haslam, and Alistair G.F. Gibb. 2019. "Reducing the Potential for Injury in the Home. How Can Ergonomics Help?”. figshare. https://hdl.handle.net/2134/8355. 
This item was submitted to Loughborough's Institutional Repository (https://dspace.lboro.ac.uk/) by the author and is made available under the following Creative Commons Licence conditions.

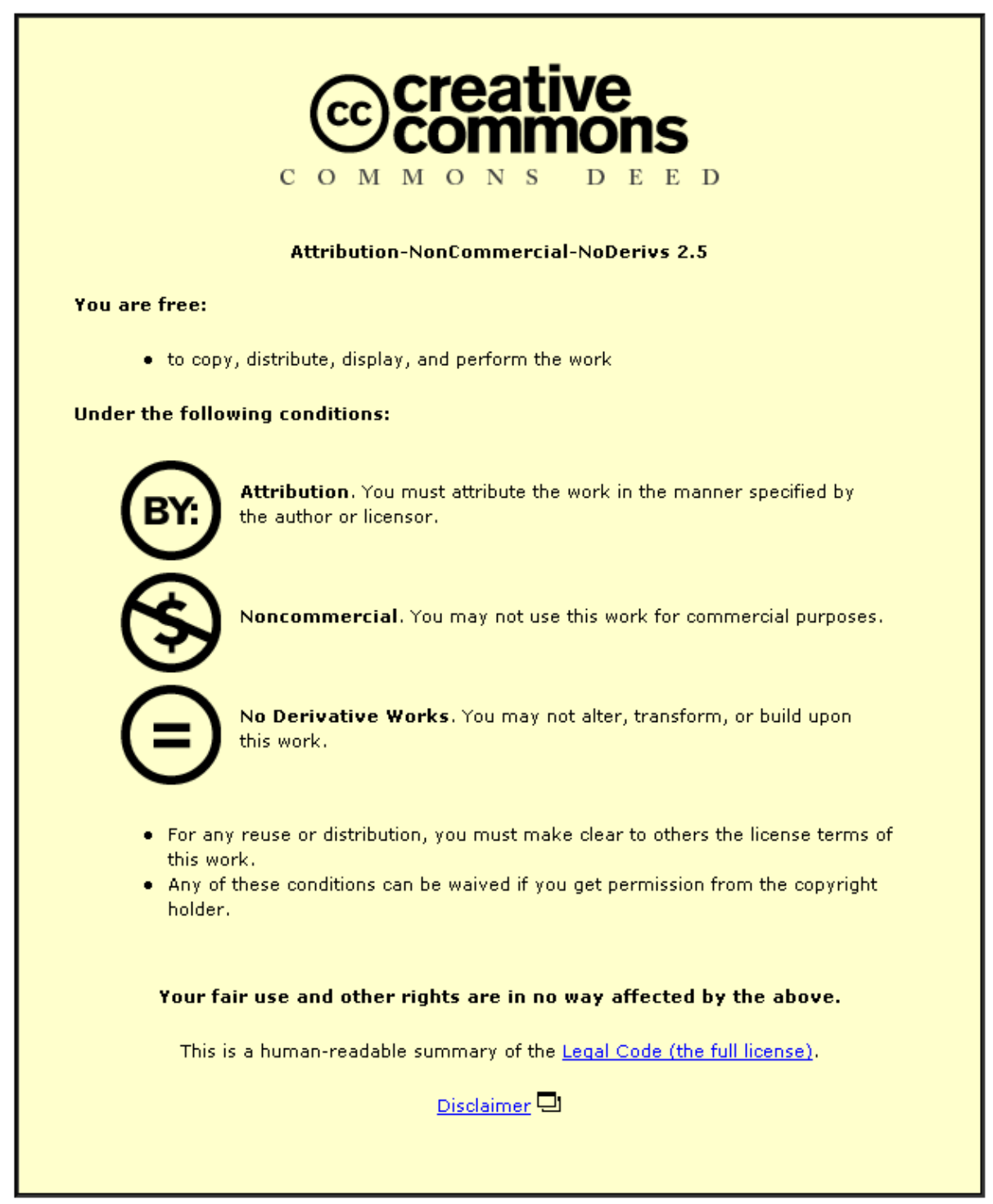

For the full text of this licence, please go to: http://creativecommons.org/licenses/by-nc-nd/2.5/ 


\title{
REDUCING THE POTENTIAL FOR INJURY IN THE HOME. HOW CAN ERGONOMICS HELP?
}

\author{
H.J. McDermott ${ }^{1}$, R.A. Haslam ${ }^{1}$ and A.G. Gibb ${ }^{2}$ \\ ${ }^{1}$ Health \& Safety Ergonomics Unit, Department of Human Sciences, \\ Loughborough University, Loughborough, Leicestershire LE11 3TU \\ ${ }^{2}$ Department of Civil and Building Engineering, Loughborough University, \\ Loughborough, Leicestershire LE11 3TU
}

\begin{abstract}
Within the UK we are experiencing a massive housing development programme with a commitment from government to increase the number of completed dwellings by $25 \%$ annually. Improving the design quality of new housing is a national priority and the research reported here aimed to verify how dwelling design interacts with human behaviour and how alternative design of new dwellings may reduce the potential for accidental injury within the home. Unsolicited questionnaires were delivered to a large number of new properties across the UK. Occupiers reported a number of problems with design features which had led to dissatisfaction and in some cases occupier modification. These findings support and validate previous work and reinforce how ergonomics principles in dwelling design may complement other strategies to improve occupier wellbeing and satisfaction.
\end{abstract}

\section{Introduction}

Housing is a key policy issue for both central and local government. In the United Kingdom, due to increased demand for home ownership we are experiencing a massive housing development programme. There is a commitment from government to increase the rate of house building from 150,000 completed dwellings per year to 200,000 completions annually by 2016 (ODPM, 2005). The majority of these completed dwellings will be housing marketed for private ownership.

Private house-building firms provide the bulk of all new housing within the UK and it is important that the housing that is provided meets the needs of those who purchase it (Leishman et al., 2004), yet there has been very little post occupancy evaluation within this sector (CABE, 2005b). Whilst usability and user involvement have become an established part of the product design process, this is not the case within architectural design (Luten, 2006). In a report by the Commission for Architecture and the Built Environment (CABE, 2005a), it was reported that the vast majority of new housing in the north of England is failing in relation to design quality. In a more comprehensive publication by the same organisation, (CABE, 2005b), recurring problems reported by 
residents within new dwellings included a lack of space to meet changing needs, poor quality of construction, and concerns in relation to the provision of car parking.

There is now an established body of literature which focuses on the design of dwellings and how careful design can reduce the potential for unintentional injury within the home, (Roys, 2001; Moore \& Ormandy, 2004; Stevenson, 2006). Evaluation studies have shown that primary protection through modification of design is an effective method of reducing accident incidence (Rennie \& Ford 1995) yet despite this, nearly 3 million people are injured each year within their home (DTI, 2003).

Ergonomics plays an important role in increasing usability and this can be usefully applied to the built residential environment. Whilst the house building industry within the UK has been criticised for being producer led as opposed to consumer led (Leishman et al., 2004), there are calls for residents views and perceptions to be incorporated into the dwelling design process (CABE, 2005b). Until now, there has been very little research examining house purchasers' needs and preferences and little is known about the extent to which new build housing meets people's needs (Leishman et al., 2004).

Previous research undertaken by the authors (McDermott et al., in press) aimed to understand how occupiers interacted with the design of new homes. The study identified a number of unsafe behaviours practised by occupiers as a result of their interaction with their brand new home. During an exploratory study participants reported interfering with the self-closing mechanism on internal fire doors, accessing the loft space via unsafe means and blocking internal air bricks which were installed to prevent the build up of noxious fumes. The research also identified a number of building features which participants had difficulty with, including, inadequate storage provision, inadequate parking provision and insufficient lighting. These problems had led to additional unsafe behaviours on the part of residents.

The research reported in this paper aimed to establish and verify if the unsafe behaviours and design issues reported in our earlier study were prevalent within new build housing throughout the UK. Improving the quality of new housing design is a national priority (CABE, 2005a) and a comprehensive understanding of the common problems faced by occupiers would assist developers and design professionals in designing homes that are compatible with human needs.

\section{Methods}

With the cooperation of a local house builder, unsolicited questionnaires were distributed by post to all individuals who had completed a purchase of a brand new dwelling in the previous 12 months. In total, 794 questionnaires were sent to households supported by a letter of introduction by the house builder. A self-addressed freepost envelope was included to facilitate the return of completed questionnaires.

The questionnaire consisted of 4 sections. Section 1 requested personal data from respondents, such as age, gender and the composition of the dwelling. Section 2 requested information about the type of property purchased and the length of occupation. Section 3 contained questions relating to the design of the property and were derived from the findings of a previous qualitative study (McDermott et al., 2006), which had identified a number of problems arising from the interaction between occupier behaviour and design. These problems were incorporated into closed questions within the questionnaire where respondents were requested to answer yes or no in relation to whether the design was present in their home and also whether this had caused them any difficulties. Following 
each section of questions on a design issue, respondents were given the opportunity to add any comment or provide further information. In the final section of the questionnaire, respondents were asked to provide information about any additional concerns they had in relation to any aspect of their home not covered in the questionnaire.

Descriptive statistics were used to identify the distribution of property types and individual design issues. Logistical regression was used to predict which aspects of each design influenced consumer satisfaction. The qualitative responses provided by respondents have been used to support the quantitative findings.

\section{Results}

\section{Personal information}

A total of 142 responses were returned to the researcher, a response rate of $17.8 \%$. Of those who responded, $40.1 \%$ were male and $59.2 \%$ were female $(0.7 \%$ missing data). A wide range of age groups were represented (18-25 (18.3\%), 26-35 (44.4\%), 36-45 (18.3\%), 46-55 (7.0\%), 56-65 (7.7\%) and over 65 (2.8\%), missing data (1.4\%). A range of house types were described; terraced house (12\%), semi-detached house (59.2\%), detached house (26.1\% and other (2.8\%). Of those responding, $22.5 \%$ lived alone, $6.3 \%$ were single parents living with children, $26.8 \%$ lived with their spouse/partner with children and $44.4 \%$ lived with their spouse/partner with no children. The value of the properties described varied between $£ 50,000-£ 99,000$ and $£ 150,000-£ 199.000$, and the average length of occupation of the properties was between 6 and 9 months. Of the 142 responses, 137 were owner occupiers and 2 were private tenants (2.1\% missing data).

\section{Dwelling features}

All 142 properties had a private garden. A large number of participants $(n=82)$ reported that their garden was on a slope. Where it was reported that the garden was sloped, $51.2 \%$ of these participants $(n=42)$ reported difficulties associated with the slope in their garden. One of the main difficulties reported which arose due to a slope was that of flooding. A sloped garden also caused maintenance difficulties for some participants. One participant living in a semi-detached dwelling commented:

'Non level nature of the garden makes maintenance difficult'

Another participant described landscaping the garden because of the slope:

'Myself and my partner have landscaped it ourselves! I wouldn't have enjoyed having a large slope'

A private garage was built with 103 of the properties. Of these, 71 were attached to the property. Only 53 participants reported using the garage for a vehicle and 87 participants reported using their garage for storage of household items. Some participants reported difficulties because their garage did not contain any lighting $(n=27)$ and also because there was no electricity supply within the garage $(n=25)$. This had led to occupier modification in some cases:

\section{'I fitted electricity after completion' and}

'I put the electricity in myself as the builders refused to'.

A light had been fitted in 72 of the properties, but this was not always in a sensible position within the garage. One participant whose garage was attached to the property said:

'The light is in a stupid place - not in easy reach if entering from house [...]so in complete darkness till light switch reached' 
A number of participants $(n=15)$ commented that the garage was too small for their needs. One participant wrote:

'If park the car in, cannot get out!!'

Participants reported insufficient parking facilities for their needs. A private driveway was attached to 125 of the properties and communal parking facilities were provided with 31 homes. Of those with a private driveway, 64.1\%, $(n=42)$ reported that this was insufficient for their needs. A number of participants added comments about the size of their driveways, these were described as being too small or too narrow. One participant with small children described the problem:

'Driveway too narrow for getting 2 small children out of each side of car'

Where communal parking areas were provided $(21.8 \%$ of properties, $\mathrm{n}=31)$, inconvenience or difficulties were reported by some participants $(n=15)$ and concerns were expressed due to this area being unlit during the hours of darkness by others ( $\mathrm{n}=$ 15). One participant reported:

'living alone with a baby I don't park at night as feel very unsafe'

In addition, difficulties unloading vehicles due to car parking arrangements were reported by 24 participants. One occupier of a terraced property wrote:

Unloading can be difficult at times as the parking area is located at the rear of the property which means coming through the garden and back patio doors'

Self-closing internal fire doors were fitted in $35.9 \%$ of the homes $(n=51)$. No fire doors were fitted in $59 \%$ of homes $(n=84)$ and in $3.5 \%$ of homes $(n=5)$ the occupiers did not know if the internal doors were fire doors (missing data, $1.4 \% \mathrm{n}=2$ ). Of the 51 homes with fire doors, information regarding this safety feature had been given to only 19 properties. In $70.6 \%$ of properties with fire doors $(n=36)$ occupiers reported propping these open in some way. In $19.6 \%(n=10)$, occupiers reported having removed the selfclosing mechanism. In $23.5 \%(n=12)$ participants reported finger trapping injuries due to the fire doors. A number of reasons were listed by participants for disabling their fire doors, these included inconvenience, concern of injury to children, concern of injury to pets, inadequate light when doors closed and noise. One participant wrote:

'They slam shut which is dangerous. We are constantly disturbed by our neighbour's doors slamming'

A fire escape window was fitted in $38.7 \%$ of properties $(n=55)$, no such window was fitted in $50.7 \%$ of properties ( $\mathrm{n}=72$ ), in $7.0 \%$ the occupiers did not know if an escape window was fitted (missing data $3.5 \%, \mathrm{n}=5$ ). Information concerning a fire escape window was provided for only 31 of the properties. In $38.2 \%$ of properties with a fire escape window $(\mathrm{n}=21)$, this window was not lockable in any way. A restrictor, preventing the fire escape window from being opened fully which could be overridden in emergencies, was fitted to $49.1 \%(n=27)$ of the properties. A total of 7 participants reported that they felt the fire escape window in their homes presented a hazard for falls. One participant explained:

'I am concerned because you can press a button and your child could fall out upstairs windows have no locks'

All but 4 of the properties were built with a loft (accessible roof void) and 103 participants had accessed this space since moving into their property. In 4 cases a ladder was not required to access the loft but in the remaining properties a fitted access ladder had been fitted by the construction company in only 1 of the properties. A fitted loft ladder had been installed by a further 9 participants subsequent to occupation. In 89 of the properties, access to the loft was gained in various ways; by using a portable ladder ( $\mathrm{n}=$ 
79), by using furniture to stand on $(\mathrm{n}=25)$, with the assistance of another person ( $\mathrm{N}=$ 39). One participant explained that this area was difficult to access:

'No ladder, no light, difficult to access'

In 5 of the properties with a loft space, an electricity supply to that area was installed by the house builder. In an additional 7 homes, the occupiers had installed electricity subsequent to moving in. In addition to a power supply, a light had been installed in the loft in 5 properties by the house builder, and in the other 98 homes with a loft, no light was provided. In 5 of these properties, the occupiers have installed a light themselves. A number of occupiers, $(\mathrm{n}=8)$, reported that they had been advised not to board out or use their loft for storage, one such participant wrote:

'Told not to store anything in it, everyone needs loft space - stupid idea'

Air ventilation bricks, installed to prevent the build up of carbon dioxide and other noxious gases, were fitted in 61 properties. In 17 cases, these caused a draught within the property and 3 participants stated that they had blocked these with furniture or by some other means. One participant commented:

'Noisy if wind is blowing'

In 16 properties, occupiers reported that the water temperature was too hot and in 6 properties scalding had occurred due to excessive hot water temperatures. One participant explained that a child had been scalded:

'One of the children scalded their hand before the water temperature was turned down' A hot water thermostat, allowing occupiers to alter the temperature of the hot water was fitted in 112 of the homes and mixer taps, allowing hot and cold water to mix at source were fitted in 91 properties. However, 10 participants reported that although mixer taps were fitted, these did not actually mix the water to prevent scalding.

Sloped internal ceilings were reported in 48 of the properties. In 33.3\% $(n=16)$ of these homes, some person had hit their head on the sloped ceilings. One participant described this occurring in the lounge:

'Sloped ceiling part of underside of staircase [...] people do hit their head on it as our settee fits under'

In $20.8 \%$ of the properties $(n=10)$ the sloped ceilings led to other problems. For example, when erecting curtain poles or moving furniture. One participant commented: 'can't fit a curtain pole'

Sloped access was provided for 48 of the properties and participants from 35 of these properties stated that this path becomes slippery in wet and icy conditions. One participant described this as a problem:

'I have complained about this on so very many occasions as slipped holding my little boy' Another participant described how even a slight incline was a problem for an elderly relative:

'Only very slight incline, was only a problem for my grandma in winter'

Newel posts are located at the top and bottom of a stair case and positioned at stair turns for structural support and these were a feature in 37 of the properties from this study. Participants from $16.2 \%$ of these properties $(n=6)$ reported people hitting their head on this feature. In one property the occupants had removed part of the newel post.

Of the 142 properties, a services map was issued to $18.3 \%$ of these properties $(n=26)$. A services map was not provided by the house builder for $79.6 \%$ of the properties $(n=$ 113 ), (missing data $=2.1 \%, n=3$ ). Other information (written or verbal) was provided in $25.4 \%$ of cases ( $n=36$ ) but for the remaining $71.8 \%$ of participants, $n=102$, no information was provided, (missing data $=2.8 \%, \mathrm{n}=4$ ). When putting up pictures, $28.2 \%$ 
of participants, $n=40$, reported that they used a services detector tool to locate the position of pipes and wires before drilling into the walls, and $84.5 \%(n=120)$ stated that they did consider where the service cabling and water pipes might be located. A total of $16.9 \%$ $(n=24)$ stated that they had drilled into the walls without considering where the water pipes or electricity service cables might be located. In 4 cases, this had resulted in the participant drilling through a water pipe or an electricity cable.

Some participants reported that although they used a services detection tool to locate the position of services within the wall, this would not detect the location of modern water pipes because they were made from plastic. One participant commented:

'Water pipes are plastic, so detecting tool wouldn't work'

Another made a similar statement:

'Plastic coated pipes means we cannot use a detection tool - just have to guess' In one instance, this had prevented the participant from erecting any pictures:

'The water pipes are plastic (I was told) and run up the wall from idle of radiator. I have therefore not put up any pictures.'

One participant reported on the technique used to locate the pipes within their home:

'Due to plastic pipes we have had to put the central heating on before putting pictures up. Pipes 'loop' in the wall rather than following straight line'

One participant explained that they had drilled into a pipe whilst undertaking a DIY task: 'Drilled into water pipe whilst putting up outside light'

Within the questionnaire, 7 participants made a written comment concerning the lack of information provided about the service cabling and water pipes. These comments indicated that more information would be of benefit to new home owners:

'To be informed where they are would be beneficial'

And

'Could do with more information'

A home information pack, containing information about the new home is provided to new occupiers as a standard procedure by the majority of house builders. Of the sample responding to this questionnaire, $59.2 \%$ of occupiers $(n=84)$ had read the whole information pack provided by the house builder, $33.8 \%(n=48)$ reported having read some of this pack. Only $76.1 \%$ of participants $(n=108)$ reported that they found this to be informative. A number of comments were made regarding the level of information provided:

'Rubbish, not relevant'

'Seems to give info to cover the builder! Not for the home owners benefit' 'Some information was missing, some not relevant (e.g. for the wrong house). Most was common sense'

However, one participant made a very positive comment in relation to the information they had received:

'We have found the information pack the most informative one we have come across'

In $50.0 \%$ of properties $(n=71)$ the windows were fitted with a window lock which was operated with a key. In $57.0 \%$ of properties $(n=81)$ the windows were fitted with a window lock which was operated through the use of a button (In a number of properties, participants reported having both types of locking mechanisms on different windows). The windows within the properties were reported to be kept locked in $71.8 \%$ of properties $(\mathrm{n}=102)$, and $64.8 \%$ of participants who had at least some windows which were lockable with a key reported that they hid the keys for the window locks. Only $12.7 \%$ of participants $(n=18)$ stated that the keys for the window locks were kept by the windows. 
In some cases, participants reported that although the windows within their property were fitted with locks administered with a key, the keys had not been supplied by the house builder. One participant wrote:

'Some windows are lockable with a key, but no keys supplied'

And in another case, the participant wrote that insufficient keys had been provided:

'Only one key given for two windows in separate rooms'

Participants from $58.5 \%$ of properties $(n=83)$ stated that at the time they purchased their property there was insufficient storage provision within their homes, and 55.6\% $(n=79)$ stated that since moving in they had created extra storage for themselves.

Amongst the problems reported by participants, the lack of facilities to store common essential items such as an ironing board or vacuum cleaner was a common theme. One participant described the situation:

'Ridiculous - not one cupboard in whole house. Ironing board \& ironing basket squeezed in airing cupboard, hoover, mops and buckets in garage, all homes need a

And another commented: cupboard'

' 3 bed roomed home - not one fitted cupboard - downstairs or upstairs. Where do people put ironing board/hoover'?

In addition to these comments, a number of other comments were made on the storage facilities within the kitchen. The following are examples of the participants' comments written on the questionnaires:

'Kitchen storage totally unacceptable for a family home [...] No storage for hoovers, coats, no downstairs storage at all'.

'This is a 4 bedroom family home, we find there is not enough storage space, especially in the kitchen'.

'Not enough storage space in the kitchen, poorly designed'.

Some participants had created extra storage space themselves:

'We added extra shelving to the kitchen cupboards as there was a lot of wasted space'. 'I have put shelving into the airing cupboard'

Whilst for others, the addition of extra storage was planned:

'Storage facilities very poor, we will add storage in the future, badly designed, very disappointed'

\section{Discussion}

This study provides a unique insight into the views of a large number of residents on the design of new housing. The findings also support and verify previous findings reported by the authors (McDermott et al., in press). In our previous work a number of dwelling features were found to be problematic for residents leading to an increased risk of injury or ill-health. The findings reported here highlight that these problems are not constrained to one geographical area or to one particular house builder, but are prevalent throughout new homes within the UK.

A number of the problems reported by occupiers during the course of this study

If all of the environmental parameters were considered within architectural design this would lead to improvements in the usability of our built environment (Luten, 2006).

Although Ergonomics has traditionally been associated with the design of work and work 
environments, there is an opportunity now for ergonomic values to be applied to dwelling design, thereby improving the usability of our new homes.

These findings present a challenge to those involved in the design and planning of new dwellings. With the current drive for design quality, (CABE, 2005a), there remains scope for improvement within a supportive legislative framework. Developers and designers need to be aware of the needs and views of residents in order to be able to incorporate effective changes into their designs.

\section{References}

Commission for Architecture and the Built Environment (2005a) Housing Audit. Assessing the design quality of new homes in the North East, North West and Yorkshire \& Humber. CABE, London.

Commission for Architecture and the Built Environment (2005b) What it's like to live there: the views of residents on the design of new housing. CABE London.

Department of Trade and Industry (2003) $24^{\text {th }}$ (Final) Report of the Home and Leisure Accident Surveillance System - 2000, 2001 and 20002 data. Department of Trade and Industry, London.

Luten, I. (2006) Ergonomic diversity, an issue in architectural design. Proceedings of the Triennial Congress of the International Ergonomics Association, Maastricht, Netherlands. ISSN 0003-6870 [CD-ROM]

Leishman, C., Aspinall, P., Munro, M. \& Warren, F.J. (2004) Preferences, quality and choice in new-build housing. Joseph Rountree Foundation.

McDermott, H., Haslam, R. \& Gibb, A. (In press) The interaction between design and occupier behaviour in the safety of new dwellings. Accident Analysis \& Prevention doi:10.1016/j.aap.2006.07.011.

Moore, R. \& Ormandy, D. (2004) Home Safety in the UK.: Review of the Influence of Human and Housing Factors. Reviews on Environmental Health 19; 3-4.

Office of the Deputy Prime Minister (2005) Government Response to Kate Barker's Review of Housing Supply: The Supporting Analysis. HMSO, London. Product code 05 HC 03529.

Rennie, D.M. \& Ford, N.J., 1995. Design of dwellings and accidents involving children. The Royal Institution of Chartered Surveyors: London. ISBN 0-85406739-6.

Roys, M. (2001) Serious stair injuries can be prevented by improved stair design. Applied Ergonomics 32 (2001) 135 - 139.

Stevenson, M. (2006) Building safer environments: injury, safety, and our surroundings. Injury Prevention 12: 1 - 3. 